\title{
Properties of Hydrophilic Mineral Wool for Desalination of Historical Masonry
}

\author{
Iñigo ANTEPARA, Zbyšek PAVLÍK*, Jaromír ŽUMÁR, Milena PAVLÍKOVÁ, \\ Robert ČERNÝ
}

\author{
Department of Building Materials, Faculty of Civil Engineering, Czech Technical University, 16629 Prague, Czech \\ Republic
}

cross $^{\text {ref }}$ http://dx.doi.org/10.5755/j01.ms.22.1.7333

Received 15 June 2014; accepted 26 December 2014

\begin{abstract}
Hydrophilic mineral wool (HMW) is considered as a possible alternative to the commonly used cellulose in desalination of historical masonry. HMW also allows water and salt solutions transport along the hydrophilic fibres, which is the necessary condition for its possible application for desalination measures, but contrary to cellulose it is inorganic material, which reduces maintenance of the poultice. On this account, the hygric transport and storage properties of newly developed HMW is determined in the paper. In order to get detailed information on HMW performance, its thermal properties are measured as well. For its basic characterization, bulk density, matrix density, saturation moisture and salt content, and apparent total open porosity are accessed. The results are in good agreement with those published in literature for similar types of HMW. The process of drying of three different types of sandstone, as typical materials frequently used in historical buildings, using HMW board is monitored to analyse the practical applicability of the proposed desalination treatment. The obtained results show that HMW slows the drying process. However, the final level of drying is the same as without the HMW, which indicates the possible applicability of studied HMW for desalination purposes.

Keywords: hydrophilic mineral water and salts transport properties, desalination.
\end{abstract}

\section{INTRODUCTION}

Mineral wool based materials are frequently used in various applications, being their most widespread use in building construction as thermal insulation boards [1]. Nevertheless, they can also be utilized for acoustic insulation, fire protection, cement reinforcement, pipe insulation and as synthetic soils for plant growing. Many mineral wool products are provided with hydrophobic substances because the presence of water in the material is undesirable for the majority of applications. In this way, its thermal insulation properties are not affected, as water in mineral wool significantly increases its thermal conductivity.

However, the capacity of mineral wool for absorption of hygroscopic moisture is very low and its water vapour diffusion permeability very high, which could result in condensation in the material. In case the mineral wool products are used as interior thermal insulation, water could accumulate in the lower parts of the boards and subsequently loss thermal insulation properties and damage the whole thermal insulation system.

Hydrophilic additives are seldom used in mineral wool products. Practically the only notable application of hydrophilic mineral wool is in the form of synthetic soils for plant growing (green roofs as a water reservoir [2]), where water saturation of the material is necessary for its proper function. However, the capability of fibrous materials with hydrophilic substances to transport rapidly liquid water [3] could make them desirable for a variety of other applications, where such favourable hygric properties

\footnotetext{
* Corresponding author. Tel.: +420 224 355436; fax: +420 224357071.

E-mail address: zbysek.pavlik@fsv.cvut.cz (Z. Pavlik)
}

could be conveniently employed. As the most prospective new possible ways of application of HMW products can be considered their use in interior thermal insulation systems [4], [5], in drying-out of flooded buildings [6] and in desalination of historical buildings.

In this paper, basic physical, hygric and thermal parameters of commercial HMWs are presented. First, bulk density, matrix density, and total open porosity of research materials are accessed. Water vapour transport in studied HMWs is characterized by measurement of water vapour permeability, water vapour diffusion coefficient and water vapour resistance factor. Liquid water transport and possible transport of salt solutions are described on the basis of sorptivity concept using sorption experiment. The absorption capacity for accumulation of water vapour is evaluated using sorption and desorption isotherms measured by dynamic sorption device. The effect of moisture content on thermal properties is also studied. Finally, drying of sandstone as typical porous building stone using HMW layer from the exterior side is monitored to demonstrate the dehumidification potential of hydrophilic mineral wool.

\section{EXPERIMENTAL}

HMW materials manufactured by Rockwool CZ, potentially applicable for desalination purposes were analysed. Original mineral wool board having thickness of 120 was analysed as sold as well as its particular layers soft (thickness $100 \mathrm{~mm}$ ) and hard (thickness $20 \mathrm{~mm}$ ) that were measured separately. Within the particulars experiments, fibres and fibres layers orientation was considered. 


\subsection{Hydrophilic mineral wool characteristics}

After analysing the matrix density of studied materials measured by the helium pycnometry, the following fundamental physical material characteristics were attained. The bulk density $\rho_{b}\left(\mathrm{~kg} / \mathrm{m}^{3}\right)$ was determined using the gravimetric method. The total open porosity $\psi\left(\mathrm{kg} / \mathrm{m}^{3}\right)$ was calculated as

$\psi=1-\frac{\rho_{b}}{\rho_{\text {mat }}}$.

The measurement of basic parameters took place in a conditioned laboratory at the temperature of $23 \pm 1{ }^{\circ} \mathrm{C}$ and $25-30 \%$ relative humidity. Each result represents the average value from four to five measured values. The expanded relative uncertainty of applied testing method is $10 \%$.

\subsection{Water vapour transport properties}

The cup method was used for the determination of water vapour transport properties [7]. The measurement was carried out in steady state under isothermal conditions. It was based on 1-D water vapour diffusion, measuring the diffusion water vapour flux through the specimen and using the values of partial water vapour pressures in the air under and above the specific specimen surfaces. The steady-state values of mass loss or mass gain determined by linear regression for the last five readings were used for the determination of water vapour diffusion coefficient. In the dry cup arrangement, the sealed cup containing silica gel, which maintained the relative humidity of about $1.5 \%$ was placed into a controlled climatic chamber with $50 \%$ of relative humidity. In the wet cup method, the sealed cup contained saturated water solution of $\mathrm{K}_{2} \mathrm{SO}_{4}$ with an equilibrium relative humidity close to $98 \%$. Within the measurement, the relative humidity in the cup was continuously monitored by capacity humidity sensors. The water vapour diffusion coefficient $D\left(\mathrm{~m}^{2} / \mathrm{s}\right)$ was calculated from the measured data according to the Eq. 2 .

$$
D=\frac{\Delta m \cdot d \cdot R \cdot T}{S \cdot \tau \cdot M \cdot \Delta p_{p}},
$$

where $\Delta m(\mathrm{~kg})$ is the mass of water vapour diffused through the sample, $d(\mathrm{~m})$ the sample thickness (always around $20 \mathrm{~mm}), S\left(\mathrm{~m}^{2}\right)$ the area of specimen surface (around $81 \mathrm{~mm}^{2}$ ), $\tau$ (s) the period of time corresponding to the transport of mass of water vapour $\Delta m$, and $\Delta_{\mathrm{pp}}(\mathrm{Pa})$ the difference in partial water vapour pressure in the air under and above specific specimen surface. $R(8.314 \mathrm{~J} / \mathrm{K} / \mathrm{mol})$ is the universal gas constant, $M(0.018 \mathrm{~kg} / \mathrm{mol})$ the molar mass of water, and $T(\mathrm{~K})$ the absolute temperature.

Using the measured water vapour diffusion coefficient, the water vapour diffusion resistance factor $\mu(-)$, which is the parameter most frequently used in building practice, was determined as

$\mu=\frac{D_{a}}{D}$,

where $D_{a}\left(\mathrm{~m}^{2} / \mathrm{s}\right)$ is the diffusion coefficient of water vapour in air.

Water vapour diffusion permeability $\delta(s)$ was calculated using Eq. 4.
$D=\delta \frac{R T}{M}$.

\subsection{Sorption and desorption isotherms}

The sorption and desorption isotherms describe the thermodynamic relationship between relative humidity of material environment and its equilibrium moisture content at constant temperature and pressure [8]. The measurement of adsorption isotherms was performed by the dynamic vapour sorption method. Initially all samples were dried at $110^{\circ} \mathrm{C}$. For the measurement, DVS-Advantage 2 device (Surface Measurement Systems Ltd.) was used. The dynamic vapour sorption method is designed to measure the equilibrium moisture content at any desired relative humidity and selected temperature in a short period of time. Device is supplied by the dry air from technical air generator. Air flow regulators control the amount of air coming through the bottle of distilled water, which creates the required relative humidity. SMS Ultra Balance guarantees the mass measurement with the precision of $0.00001 \mathrm{~g}$. To enable this sensitivity there is used an optical sensor which scan the hands of the balance where the sample is hanged. The device is designed to be able to measure in the range of temperature $5-60{ }^{\circ} \mathrm{C}+/-0.2{ }^{\circ} \mathrm{C}$. Temperature sensor PT100 controls the temperature precision of certified reference probe.

After drying, the samples were put into the chamber of DVS Advantage device, where they are hung on the bowl of automatic balance in a special steel tube. Here, the experimental data were achieved at the temperature of $20{ }^{\circ} \mathrm{C}$. The samples were continuously submitted to the water vapour pressures creating relative humidities $0 ; 20$; $40 ; 60 ; 80$ and $98 \%$. The device was set on mode $\mathrm{dm} / \mathrm{dt}$ (change of mass in time) during the experiment. Fixed value of $\mathrm{dm} / \mathrm{dt}$ was initially set to be $0.0004 \mathrm{~g} / \mathrm{min}$ for all stages of relative humidity with maximum time allowed for a stage $360 \mathrm{~min}$. After either condition was satisfied, the current relative humidity stage was terminated and followed by another step.

\subsection{Sorptivity experiment}

The water absorption coefficient $A\left(\mathrm{~kg} / \mathrm{m}^{2} \mathrm{~s}^{1 / 2}\right)$ and the chloride solution absorption coefficient $A_{\mathrm{NaCl}}\left(\mathrm{kg} / \mathrm{m}^{2} \mathrm{~s}^{1 / 2}\right)$ were measured using a standard experimental setup [9]. The specimen was water and vapour-proof insulated on four lateral sides and the face side was immersed $1-2 \mathrm{~mm}$ into the distilled water or $1 \mathrm{M} \mathrm{NaCl}$ water solution. The automatic balance allowed recording the increase of sample mass. The absorption coefficients were then calculated using the Eq. 5 .

$i=A \cdot \sqrt{t}$,

where $i\left(\mathrm{~kg} / \mathrm{m}^{2}\right)$ is the cumulative mass of water or salt solution, $t(\mathrm{~s})$ is the time from the beginning of the suction experiment. The water or salt solution absorption coefficient was then employed for the calculation of the apparent moisture diffusivity $\kappa_{\text {app }}\left(\mathrm{m}^{2} / \mathrm{s}\right)$ in the form

$\kappa_{a p p} \approx\left(\frac{A}{w_{s a t}}\right)^{2}$,

where $w_{\text {sat }}\left(\mathrm{kg} / \mathrm{m}^{3}\right)$ is the saturated moisture content $[10,11]$. 


\subsection{Thermophysical properties}

The thermal conductivity and the volumetric heat capacity measurements were performed with dynamic impulse device Isomet 2104 (Applied Precision), using the needle probe in vertical position [12]. The sensor of the needle was always placed in the centre of the sample. The relative standard uncertainty of the thermal conductivity measurement was $5 \%$, and for the specific heat capacity it was $10 \%$. This data is provided by Isomet producer.

The thermal conductivity measurement of the HMW in dependence on moisture content was performed up to fully saturated state. Defined volumes of distilled water were added to each of the samples. Then, the samples were put into a plastic bag and kept several days until the moisture was uniformly distributed. The moisture dependent volumetric heat capacity was calculated using Eq. 7.

$C_{w e t}=\frac{\rho_{d r y} \cdot C_{d r y}+\rho_{\text {water }} \cdot C_{\text {water }} \cdot w}{\rho_{d r y}+\rho_{\text {water }} \cdot w}$,

where $w\left(\mathrm{~m}^{3} / \mathrm{m}^{3}\right)$ is volumetric moisture content, $C_{w e t}$ $\left(\mathrm{J} / \mathrm{m}^{3} \mathrm{~K}\right)$ volumetric heat capacity of wet sample, $\rho_{d r y}$ $\left(\mathrm{kg} / \mathrm{m}^{3}\right)$ is bulk density of dry material, $C_{d r y}\left(\mathrm{~J} / \mathrm{m}^{3} \mathrm{~K}\right)$ the volumetric heat capacity of dry material, $\rho_{\text {water }}\left(\mathrm{kg} / \mathrm{m}^{3}\right)$ density of water, and $C_{\text {water }}\left(\mathrm{J} / \mathrm{m}^{3} \mathrm{~K}\right)$ volumetric heat capacity of water.

\subsection{Drying experiment}

The drying of fully water saturated sandstone samples provided by HMW board was investigated. Within the drying experiments, three different types of sandstone (denoted NA1, NA3, NA9) coming from Czech quarries were tested. The particular samples having dimensions of $100 \times 100 \times 100 \mathrm{~mm}$ (NA3, NA9) and $70 \times 70 \times 70 \mathrm{~mm}$ (NA1) were water and water vapour proof insulated with epoxy resin on four lateral and one of frontal sides (one side remained uninsulated), and immersed into distilled water, until they were fully saturated with water. Then, the dried samples of HMW board were prepared and insulated with silicone rubber on four lateral sides. Next step was connecting the sandstone and HMW samples by uninsulated sides together. Here, the sandstone substrate and HMW board were mechanically stuck by simple construction as given in Fig. 1.

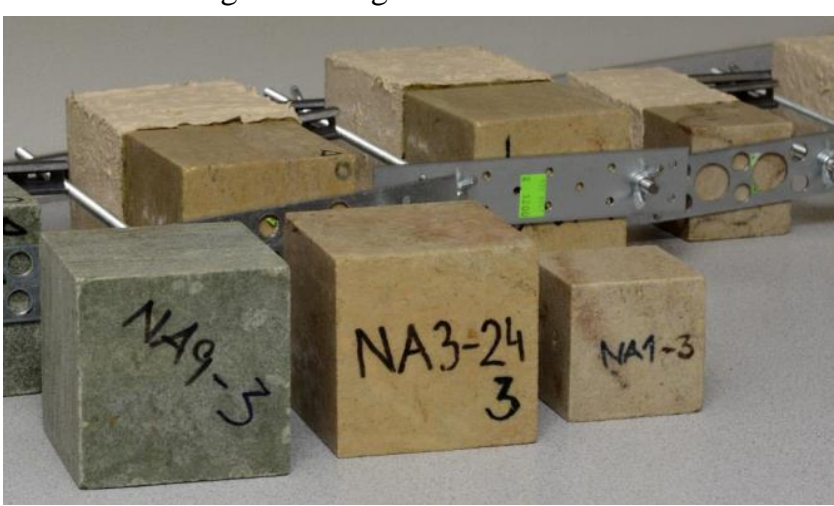

Fig. 1. Sandstone samples and arrangement of the drying experiment

For each material, one water saturated sample was not provided by the HMW, and was left freely in laboratory at temperature of $23 \pm 1{ }^{\circ} \mathrm{C}$ and relative humidity of about $25 \%$. In this way, the reference drying data was obtained.

The fibre orientation in mineral wool samples was perpendicular to the moisture transport. This experimental arrangement respects the fibre orientation in supplied insulation boards in order to simulate the moisture transport in these boards applied on the real masonry. All the studied samples were periodically weighted and mass losses caused by the drying were recorded. From this data, the time dependent history of moisture content in the studied samples was calculated.

\section{RESULTS AND DISCUSSION}

The results of the basic physical properties of tested HMW materials are given in Table 1.

Table 1. Basic physical properties of HMW materials

\begin{tabular}{|c|c|c|c|}
\hline Material & $\begin{array}{c}\text { Bulk } \\
\text { density, } \\
\mathrm{kg} / \mathrm{m}^{3}\end{array}$ & $\begin{array}{c}\text { Porosity, } \\
\%\end{array}$ & $\begin{array}{c}\text { Matrix } \\
\text { density, } \\
\mathrm{kg} / \mathrm{m}^{3}\end{array}$ \\
\hline $\begin{array}{c}\text { Commercial HMW } \\
\text { (as sold) }\end{array}$ & 95.0 & - & - \\
\hline $\begin{array}{c}\text { Soft part of } \\
\text { commercial HMW }\end{array}$ & 79.5 & 96.9 & 2557 \\
\hline $\begin{array}{c}\text { Hard part of } \\
\text { commercial HMW }\end{array}$ & 172.4 & 93.4 & 2602 \\
\hline
\end{tabular}

The studied materials proved their anticipated high porosity that ensures effective thermal insulation function. However, the high porosity also enables water vapour transport, what is also beneficial from the point of view of HMW application in insulation of older buildings that usually suffer from moisture presence. The matrix density data corresponds with the values typical for fibres.

The water transport properties measured by cup method are given in Table 2. Here, the measurement was done on samples with fibres layer oriented perpendicular to the 1-D water vapour transport. We can see that both studied layers of original HMW board exhibited similar water vapour transport parameters especially taking into account the relative measurement uncertainty that is $10 \%$. The water vapour diffusion resistance factor is very low and clearly demonstrates the high rate of the water vapour transport in researched materials.

Table 5. Water vapour diffusion parameters

\begin{tabular}{|c|c|c|c|}
\hline \multirow{2}{*}{ Material } & \multicolumn{3}{|c|}{ Water vapour diffusion } \\
\cline { 2 - 4 } & $\delta, \mathrm{s}$ & $D, \mathrm{~m}^{2} / \mathrm{s}$ & $\mu,-$ \\
\hline \multicolumn{4}{|c|}{ Dry cup } \\
\hline Hard layer & $9.9 \mathrm{E}-11$ & $1.3 \mathrm{E}-05$ & 1.7 \\
\hline Soft layer & $1.0 \mathrm{E}-10$ & $1.4 \mathrm{E}-05$ & 1.6 \\
\hline \multicolumn{4}{|c|}{ Wet cup } \\
\hline Hard layer & $1.0 \mathrm{E}-10$ & $1.3 \mathrm{E}-05$ & 1.7 \\
\hline Soft layer & $1.0 \mathrm{E}-10$ & $1.4 \mathrm{E}-05$ & 1.7 \\
\hline
\end{tabular}

Sorption and desorption isotherms are presented in Fig. 2. Both studied materials have very low absorption capacity for water vapour as well as negligible hysteresis of sorption process. This data means that HMW exposed to the high relative humidity environment does not change its properties related to the moisture storage. 


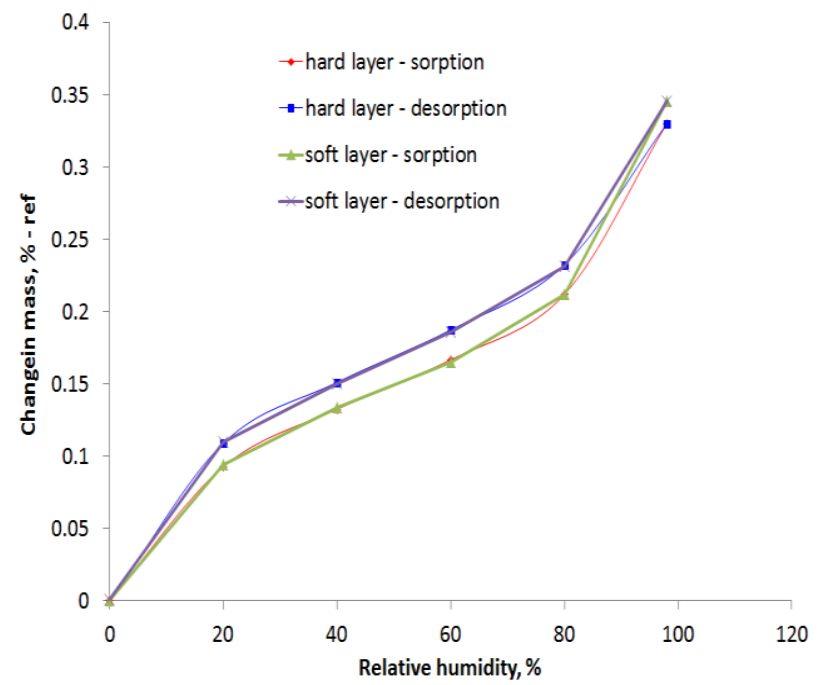

Fig. 2. Sorption and desorption isotherms

Parameters characterizing the liquid moisture transport in the tested materials are summarized in Table 3. Here, the transport of water or salt solution was realized in parallel as well as perpendicularly to the orientation of fibres layers.

Looking at data in Table 3, one can observe high values of moisture diffusivity what is promising finding for application of the tested materials in desalination of salt laden masonry.

Table 3. Water transport parameters

\begin{tabular}{|c|c|c|c|}
\hline \multirow{2}{*}{ Layer } & \multirow{2}{*}{ Fibre direction } & \multicolumn{2}{|c|}{ Water transport parameters } \\
\hline & & $A, \mathrm{~kg} / \mathrm{m}^{2} \mathrm{~s}^{1 / 2}$ & $\kappa_{a p p,} \mathrm{~m}^{2} / \mathrm{s}$ \\
\hline \multicolumn{4}{|c|}{ Water } \\
\hline Hard & Perpendicular & 5.1 & $3.0 \mathrm{E}-5$ \\
\hline Hard+Soft & Perpendicular & 5.6 & $3.6 \mathrm{E}-5$ \\
\hline Soft & Perpendicular & 5.5 & $3.5 \mathrm{E}-5$ \\
\hline Soft & Parallel & 5.7 & $3.7 \mathrm{E}-5$ \\
\hline \multicolumn{4}{|c|}{$1 \mathrm{M} \mathrm{NaCl}$ - water } \\
\hline Hard & Perpendicular & 4.8 & $2.5 \mathrm{E}-5$ \\
\hline Hard+Soft & Perpendicular & 4.9 & $2.8 \mathrm{E}-5$ \\
\hline Soft & Perpendicular & 5.2 & $3.1 \mathrm{E}-5$ \\
\hline Soft & Parallel & 5.4 & $3.4 \mathrm{E}-5$ \\
\hline
\end{tabular}

In case of $1 \mathrm{M} \mathrm{NaCl}$ water solution transport, the moisture transport was slightly slower compared to the transport of pure water. However, its velocity is still very high. This we assign to the higher viscosity and density of salt solution than of water.

In Fig. 3, there is demonstrated the moisture transport into the tested materials measured within the sorption experiment. From this data, the values of water absorption coefficient presented above were calculated. Similar curves were obtained for suction of $1 \mathrm{M} \mathrm{NaCl}$ solution.

The thermal conductivity data is given in Table 4 . The measurement in dependence on moisture content was done for soft part samples only. The thermal conductivity of the dry materials is typically very low and show evidence of good thermal insulation properties. On the other hand, the presence of moisture highly accelerates the heat transport what must be always considered in practical application of the tested materials. Looking at the data measured for particular directions of heat transport, the anisotropy effect is very small, especially taking into account the measurement errors.



Fig. 3. The course of sorptivity experiment

Table 4. Thermal Conductivity of researched HMWs

\begin{tabular}{|c|c|c|c|}
\hline Material & $\begin{array}{c}\text { Moisture content, } \\
\mathrm{m}^{3} / \mathrm{m}^{3}\end{array}$ & Direction & $\begin{array}{c}\text { Thermal } \\
\text { conductivity } \\
\text { W/mK }\end{array}$ \\
\hline As sold & Dry & Perpendicular & 0.042 \\
\hline \multirow{2}{*}{ Soft part } & \multirow{2}{*}{ Dry } & Perpendicular & 0.042 \\
\hline & & Parallel & 0.040 \\
\hline \multirow{2}{*}{ Hard part } & \multirow{2}{*}{ Dry } & Perpendicular & 0.050 \\
\hline & & Parallel & 0.048 \\
\hline \multirow{2}{*}{ Soft part } & \multirow{2}{*}{0.5} & Perpendicular & 0.249 \\
\hline & & Parallel & 0.244 \\
\hline \multirow{2}{*}{ Soft part } & \multirow{2}{*}{$\begin{array}{l}\text { Fully saturated } \\
(0.93)\end{array}$} & Perpendicular & 0.546 \\
\hline & & Parallel & 0.545 \\
\hline
\end{tabular}

The volumetric heat capacity results are shown in Table 5. The heat capacity of studied HMW products significantly increases with moisture due to the high heat capacity of water. On the other hand, the volumetric heat capacity in the dry state is very low, and corresponds to the high porosity and low bulk density of tested materials.

Table 5. Volumetric heat capacity of researched HMWs

\begin{tabular}{|c|c|c|}
\hline Material & Moisture content, $\mathrm{m}^{3} / \mathrm{m}^{3}$ & $\begin{array}{c}\text { Volumetric heat } \\
\text { capacity, } \mathrm{kJ} / \mathrm{m}^{3} \mathrm{~K}\end{array}$ \\
\hline Soft part & Dry & 94 \\
\hline Hard part & Dry & 171 \\
\hline Soft part & 0.5 & 1112 \\
\hline Soft Part & Fully saturated $(0.93)$ & 3955 \\
\hline
\end{tabular}

Similar results of basic physical properties, water vapour transport properties, and thermophysical properties measured for different HMW materials were published by Jerman and Černý [13]. However, the anisotropy of these properties was not studied, and the orientation of fibres layers was not changed from one measurement to another. This data represents the significant novelty of the presented paper and can be beneficially used in further research of the studied problem as well as in building practice. Looking at the measured data of water absorption coefficient and sorptivity, it is quite clear that orientation of HMW board in building structure has crucial influence on its performance in contact with water and salt solution. 
Additionally, the drying performance of sandstone samples through the HMW layer was measured, which is presented in Fig. 4. The drying with the HMW is slower compared to the drying without HMW at laboratory conditions. However, the same drying state was reached in the end for both with and without HMW.

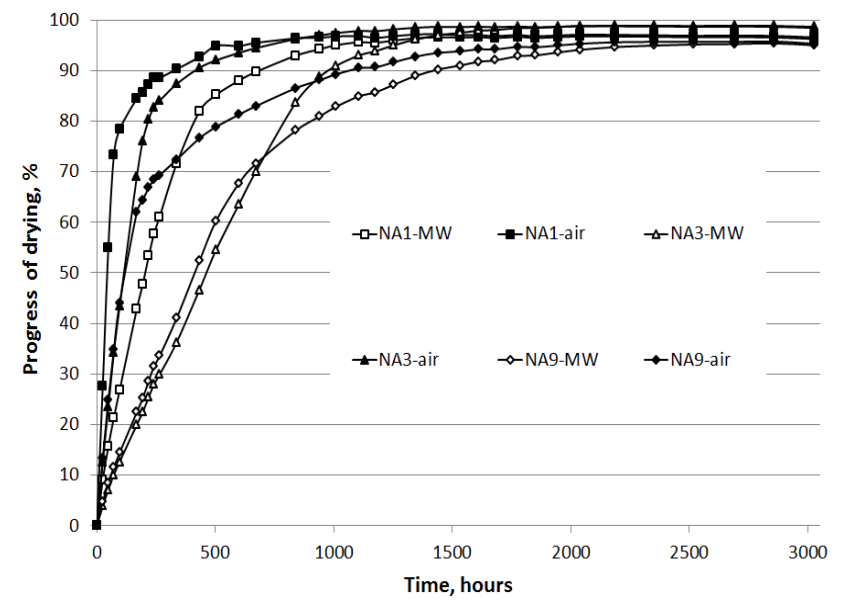

Fig. 5. Progress of drying process

The same behaviour was described by Michálek et al. [14] for a different type of sandstone having total open porosity $31.2 \%$. In that study, sandstone performance was compared with brick and autoclaved aerated concrete. Although the HMW in all researched cases decelerated the drying process, one can assume that its application as poultice material for drying and desalination can improved the thermal conditions of treated buildings and building structures during periods of the year characteristic by low climatic temperatures.

Looking at data presented in Fig. 5, one can see different drying behaviour of particular substrate materials. Materials NA3 and NA9 exhibit similar drying rate at the beginning phase of drying process, what can be assigned to their high total open porosity values (porosity of NA3 is $25.2 \%$, porosity of NA9 is $23.2 \%$ ). On the other hand, material NA1 having lower porosity $(19.7 \%)$ dried up faster. This finding we assign to the differences in pore size distribution and spatial arrangement of the pore system that can contain curved and closed pores.

\section{CONCLUSIONS}

In this paper, complete set of basic physical, hygric and thermal properties of HMW materials was accessed. The obtained data give information on moisture and heat transport in the studied materials, whereas the measured values of particular material parameters are highly promising for the practical application of the developed materials in building industry. The low thermal conductivity and the high water vapour diffusion coefficient are promising properties for the use of all tested HMWs in the interior thermal insulation systems. The performed experiments showed that liquid moisture transport in this type of material is significantly faster than in most other building materials. The high moisture diffusivity measured for penetration of water and $1 \mathrm{M} \mathrm{NaCl}$ water solution make the tested materials applicable for the desalination of masonry.
The most popular method for desalination is aqueous extraction by poulticing, and the most used poultice material is cellulose because it is easy to prepare, apply, and presents a good adhesion to the substrate at the application [15]. It can be removed from most surfaces without residue [16]. Nevertheless, HMW was used for desalination in [17], with all these advantages.

Poultices based on clay minerals are advantageous because they don't need a daily check, which is necessary for cellulose containing poultices to prevent mouldiness [16]. HMW, an inorganic material as the clay, would also avoid daily checking.

The cellulose has an undesired tendency to redistribute surface salts deeper into the surface, as it can potentially release to the substrate three times more water than a similarly thick clay poultice. Here, moisture penetration depth and distribution depend on the sorption properties of the substrate [17]. It is not possible to predict before laboratory study whether the HMW will have the same tendency as cellulose or not, but authors in [17] remarked that it was possible to control the water uptake into the masonry.

Finally, cellulose has some drawbacks, as poor water retention when applied on vertical surfaces [18], and a higher shrinkage while drying than other materials [19], which may induce a lower adhesion to the substrate during the drying of the poultice [20]. On this account, our future work will focus on whether HMW can overcome these problems.

As for the presumed application purpose, HMW looks like possible solution for salt extraction from building materials. However, the further analysis must be done, taking into account the substrate material performance and properties.

\section{Acknowledgments}

This research was supported by the European social fund within the framework of realizing the project "Support of inter-sectorial mobility and quality enhancement of research teams at Czech Technical University in Prague", project No. CZ.1.07/2.3.00/30.0034.

\section{REFERENCES}

1. Pavlík, Z., Černý, R. Experimental Assessment of Hygrothermal Performance of an Interior Thermal Insulation System Using a Laboratory Technique Simulating on-site Conditions Energy and Buildings 40 (5) 2008, pp. $673-678$.

2. Jim, C. Y., Tsang, S. W. Modeling the Heat Diffusion Process in the Abiotic Layers of Green Roofs Energy and Buildings 43 (6) 2011: pp. $1341-1350$.

3. Jiřičková, M., Černý, R. Effect of Hydrophilic Admixtures on Moisture and Heat Transport and Storage Parameters of Mineral Wool Construction and Building Materials 20 2006: pp. $425-434$

4. Pavlík, Z., Jiřičková, M., Pavlík, J., Černý, R. Interior Thermal Insulation System Based on Hydrophilic Mineral Wool Journal of Building Physics 29 2005: pp. 21-35.

5. Pavlík, Z., Čenný, R. Hygrothermal performance study of an Innovative Interior Thermal Insulation System Applied Thermal Engineering 29 (10) 2009: pp. 1941-1946. 
6. Maděra, J., Černý, R. Computational Simulation of a NonTraditional Method for Drying-Out of Building Envelopes Affected by Flood Roczniki Inzynierii Budowlanej 6 2006: pp. $71-74$.

7. Fořt, J., Pavlík, Z., Žumár, J., Pavlíková, M., Černý, R. Effect of Temperature on Water Vapour Transport Properties Journal of Building Physics 38 (2) 2014: pp. $156-169$. http://dx.doi.org/10.1177/1744259114532612.

8. Pavlík, Z., Žumár, J., Medved, I., Černý, R. Water Vapor Adsorption in Porous Building Materials: Experimental Measurement and Theoretical Analysis Transport in Porous Media 91 2002: pp. 939-954. http://dx.doi.org/10.1007/s11242-011-9884-9

9. Hall, C. Water Sorptivity of Mortars and Concretes: a Review Magazine of Concrete Research 41 1989: pp. $51-61$.

10. Roels, S., Carmeliet, J., Hens, H., Adan, O., Brocken, H., Černý, R., Pavlík, Z., Hall, C., Kumaran, K., Pel, L., Plagge, R. Interlaboratory Comparison of Hygric Properties of Porous Building Materials Journal of Thermal Envelope and Building Science 27 2004: pp. 307-325.

11. Kumaran, M.K. Moisture Diffusivity of Building Materials from Water Absorption Measurements Journal of Thermal Envelope and Building Science 22 1999: pp. 349-355.

12. Mnahoncakova, E., Jirickova, M., Pavlik, Z., Fiala, L., Rovnanikova, P., Bayer, P., Cerny, R. Effect of Moisture on the Thermal Conductivity of a Cementitious Composite. International Journal of Thermophysics 27 2006: pp. $1228-1240$. http://dx.doi.org/10.1007/s10765-006-0073-y

13. Jerman, M., Černý, R. Effect of Moisture Content on Heat and Moisture Transport and Storage Properties of
Thermal Insulation Materials Energy and Buildings 2012: pp. 39-46.

14. Michálek, P., Tydlitát, V., Jerman, M., Černý, R. Desalination of Historical Masonry Using Hydrophilic Mineral Wool Boards WIT Transactions on Modelling and Simulation 46 2007: pp. 377-388.

15. Heritage, A.A., Sawdy, A., Funke, F., Verges-Belmin, V., Bourges, A. How Do Conservators Tackle Desalination? An International Survey of Current Poulticing Methods CHRESP: 8th EC Conference on Sustaining Europe's Cultural Heritage, Ljubljana, Slovenia, National and University library 2008: pp. 58-59.

16. Auras, M. Poultices and Mortars for Salt Contaminated Masonry and Stone Objects. Salt Weathering on Buildings and Stone Sculptures, Proceedings from the international conference' 2008 2008: pp. 197-217.

17. Mertz, J. D., Loutrel, P. Le Dessalement des Tuffeaux du Chateau des Duc de Bretagne a Nantes par la Méthode de Nettoyage Tollis Pierre Actual 779 (7) 2001: pp. 68-75.

18. Vergès-Belmin, V., 2Heritage, A., Bourges, A. Powdered Cellulose Poultices in Stone and Wall Painting Conservation Myths and Realities Studies in Conservation $56(4)$ 2011: pp. $281-297$.

19. Lombardo, T., Simon, S. Laboratory Study on Desalination by Poultices. European research on cultural heritage. State of the art studies Proceedings of the ARCCHIP Workshop supported from the EC 5th FP Project No. ICA1-CT-2000700135 2006: pp. 275-286.

20. Bourgès, A.V. Vergès-Belmin, V. Application of Fresh Mortar Tests to Poultices Used for the Desalination of Historical Masonry Materials and Structures/Materiaux et Constructions 44 (7) 2011: pp. 1233-1240. 